Canadian

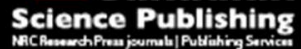

Canadian Journal of Physiology and Pharmacology Revue canadienne de physiologie et pharmacologie

\title{
The effect of short-term oral treatment with omeprazole or pantoprazole on the function of polymorphonuclear neutrophils
}

\begin{tabular}{|r|l|}
\hline Journal: & Canadian Journal of Physiology and Pharmacology \\
\hline Manuscript ID & cjpp-2016-0232.R1 \\
\hline Manuscript Type: & Article \\
\hline Date Submitted by the Author: & 21-Aug-2016 \\
\hline Complete List of Authors: & $\begin{array}{l}\text { Kostrzewska, Maja; Uniwersytet Medyczny w Bialymstoku, Department of } \\
\text { Gastroenterology and Internal Medicine } \\
\text { Garley, Marzena; Uniwersytet Medyczny w Bialymstoku, Department of } \\
\text { Immunology } \\
\text { Ratajczak, Wioletta; Uniwersytet Medyczny w Bialymstoku, Department of } \\
\text { Immunology } \\
\text { Jablonska, Ewa; Uniwersytet Medyczny w Bialymstoku, Department of } \\
\text { Immunology } \\
\text { Jamiołkowski, Jacek; Uniwersytet Medyczny w Bialymstoku, Department of } \\
\text { Public Health } \\
\text { Dabrowski, Andrzej; Uniwersytet Medyczny w Bialymstoku, Department of } \\
\text { Gastroenterology and Internal Medicine }\end{array}$ \\
\hline Keyword: & $\begin{array}{l}\text { omeprazole, pantoprazole, polymorphonuclear neutrophils, nitric oxide } \\
\text { synthase, p38 mitogen-activated protein kinase. }\end{array}$ \\
\hline
\end{tabular}

\section{SCHOLARONE"}

Manuscripts 
The effect of short-term oral treatment with omeprazole or pantoprazole on the function of polymorphonuclear neutrophils

Maja Kostrzewska $\mathrm{MD}^{1}$, Marzena Garley $\mathrm{PhD}^{2}$, Wioletta Ratajczak-Wrona $\mathrm{PhD}^{2}$, Ewa Jabłońska $\mathrm{PhD}^{2}$, Jacek Jamiołkowski $\mathrm{PhD}^{3}$ Andrzej Dabrowski MD, $\mathrm{PhD}^{1}$

${ }^{1}$ Department of Gastroenterology and Internal Medicine, Medical University of Bialystok, Poland

${ }^{2}$ Department of Immunology, Medical University of Bialystok, Bialystok, Poland

${ }^{3}$ Department of Public Health, Medical University of Bialystok, Bialystok, Poland

Address for correspondence:

Maja Kostrzewska, MD

Department of Gastroenterology and Internal Medicine, Medical University of Bialystok, ul. Sklodowska-Curie 24A, 15-276 Bialystok, Poland tel. +48857468234 fax. +48857468506

e-mail: gastro@umb.edu.pl

Running head:

Proton pump inhibitors effect on neutrophils 


\begin{abstract}
Recent studies report an increased risk of enteric infections in patients treated with proton pump inhibitors (PPIs). Polymorphonuclear neutrophils (PMNs) play a key role in host response to bacterial infection. We have evaluated the effect of omeprazole and pantoprazole treatment on the PMNs function. Fifteen patients were treated with omeprazole $20 \mathrm{mg}$ daily and 15 patients with pantoprazole $40 \mathrm{mg}$ daily for 7 days. Treatment with omeprazole or pantoprazole had no effect on spontaneous nitroblue tetrazolium (NBT) test results. Significant increase in the percentage of phagocytes in the omeprazole group in stimulated NBT test (by 69\%) was found. Treatment with omeprazole or pantoprazole had no effect on nitric oxide (NO) concentration in the PMNs' culture supernatant and serum, cyclic guanosine monophosphate concentration in the PMNs' culture supernatant and serum as well as inducible nitric oxide synthase (iNOS) protein expression and p38 mitogen-activated protein kinase activity in PMNs. In conclusion, treatment with PPI has no effect on NO production and p38 mitogen-activated protein kinase activity in PMNs. Interestingly, short-term treatment with omeprazole but not with pantoprazole enhances PMNs reactive oxygen species production.
\end{abstract}

Key words:

cyclic guanosine monophosphate, nitric oxide, nitric oxide synthase, nitroblue tetrazolium test, omeprazole, pantoprazole, polymorphonuclear neutrophils, proton pump inhibitors, p38 mitogen-activated protein kinase. 


\section{Introduction}

In the last two decades, there is an ongoing debate about safety of the long-term use of proton pump inhibitors (PPIs). It is known that proton pumps are located not only in the gastric mucosa, but also in other tissues and cells. Such structures have been described in the large intestine, in the renal collecting tubule cells and neutrophils (Ritter et al. 1998). PPIs are commonly used in the treatment of gastric acid-related diseases, mainly gastroesophageal reflux disease, dyspepsia and peptic ulcer disease. They are generally well tolerated, with adverse events occurring in $5 \%$ of patients, mostly headache, diarrhea, abdominal pain, nausea (Martin et al. 2000; Martins de Oliveira et al. 2007; Stedman et al. 2000). Treatment with PPIs have been also linked with greater risk of Clostridium difficile-induced pseudomembranous colitis (Cunningham et al. 2003; Dial et al. 2005; Yearsley et al. 2006) and pneumonia (Gulmez et al. 2007; Laheij et al. 2004). It is possible that not only an increase in gastric $\mathrm{pH}$ predisposes to infection but also impaired neutrophil function which may have an adverse effect on human immune status. In recent years some reports suggest that PPIs may impair the function of neutrophils such as chemotaxis (Wandall 1992), adhesion to endothelial cells (Suzuki et al.1999; Yoshida et al. 2000), oxygen-derived free radical production and phagocytosis (Agastya et al. 2000; Suzuki et al. 1996).

Some regulatory functions of neutrophils in the immune system are mediated by the production of reactive forms of nitrogen, including nitric oxide (NO) (Alderton 2000; Dröge 2002). NO is a signaling molecule that plays a key role in the pathogenesis of inflammation, contributes to the regulation of apoptosis, induces vasodilatation in cardiovascular system and it is also a potent neurotransmitter at the neuron synapses. In humans, it is synthesized by the following forms of the nitric oxide synthase (NOS): neuronal (nNOS) in nervous tissue, endothelial (eNOS) in blood vessels and inducible (iNOS) in neutrophils, monocytes, macrophages, hepatocytes and bronchial epithelial cells (Alderton 2000; Dröge 2002). 
Stimulation of iNOS expression in neutrophils by pro-inflammatory cytokines leads to the production of large quantities of nitric oxide. High concentrations of NO in the mitochondria stimulate the production of superoxide anion $\left(\mathrm{O}_{2}{ }^{-}\right)$. Infiltration of leukocytes to a site of injury or infection is a characteristic feature of inflammation, and one that can be profoundly influenced by NO. Adherence of leukocytes to the vascular endothelium in response to stimulation with a chemotactic factor can be markedly suppressed by NO donors. NO has the ability to scavenge superoxide anion and may prevent superoxide anion production (Alderton 2000).

$\mathrm{NO}$ activates cytosolic guanylate cyclase (sGC), which in turn catalyzes the formation of cyclic guanosine 3',5'-monophosphate (cGMP) from GTP. cGMP mediates a wide spectrum of physiologic processes in multiple cell types within the cardiovascular system. Dysfunctional signaling at any step of the cascade - cGMP synthesis, effector activation, or catabolism - have been implicated in numerous cardiovascular diseases, ranging from hypertension to atherosclerosis to cardiac hypertrophy and heart failure (Tsai et al. 2009).

Mitogen-activated protein (MAP) kinases comprise a family of proteinserine/threonine kinases, which are highly conserved in protein structures from unicellular eukaryotic organisms to multicellular organisms, including mammals. The MAP kinases signaling pathways play a significant role in the activation of various neutrophil's functions. The members of MAP kinase family are involved in all aspects of immune response. p38 MAP kinase is associated with immune cell activation and activated by a variety of inflammatory mediators (Abraham 2005). Recent in vitro study have demonstrated the inhibitory effect of lansoprazole for signal transduction through extracellular-signal regulated kinase (ERK) 1/2 and p38 MAP kinase in stimulated neutrophils (Koshio et al. 2010).

Most of the previous studies on the effects of PPIs on polymorphonuclear neutrophils (PMNs) have been done with the use of omeprazole in vitro, in animal models and in patients 
with Helicobacter pylori infection (Agastya et al. 2000; Martin et al. 2000; Suzuki et al.1999; Wandall 1992; Yoshida et al. 2000). The overall effect of PPI on PMNs function in vivo remains controversial and most of the studies have been done with the use of omeprazole. Additionally, there is no data available on the effect of PPI on NO production by PMNs. Therefore, the aim of our study was to evaluate the effect of short-term oral treatment with omeprazole or pantoprazole on the function of PMNs with respect to NO production.

\section{Patients and methods}

Before enrolling to the study all the subjects had clinical examination and laboratory blood tests: complete blood count, concentration of C-reactive protein, fibrinogen, creatinine, urea, bilirubin, glucose, sodium, potassium in serum, activity of alanine aminotransferase and aspartate aminotransferase in serum, prothrombin time and urinalysis. The study has involved patients with normal results of physical examination and laboratory tests before enrollment. Other inclusion criteria were: no PPI treatment at least 14 days before the study, indications for use of PPI (peptic ulcer disease, gastroesophageal reflux disease), no other medications during the study. Exclusion criteria were: PPI or $\mathrm{H} 2$ receptor antagonist treatment within 14 days before the study, antibiotic use within 4 weeks before the study, current bacterial or viral infection, diabetes, cancer, immunodeficiency in medical history. The exclusion criteria did not contain nitrite/nitrate-rich diet. In our patients, the daily nitrite/nitrate consumption was not evaluated. Informed consent was obtained from all of the subjects. The study was approved by the Ethics Committee of Medical University of Bialystok.

We have prospectively enrolled 16 women and 14 men. The mean age of the subjects was $38.1 \pm 11.9$ years. Using a single-dose, randomized, open-label clinical trial design, proton pump inhibitors were orally administered, in a standard dose, for 7 days: 15 patients 
were treated with omeprazole $20 \mathrm{mg}$ per day and 15 patients with pantoprazole $40 \mathrm{mg}$ per day, taken 30 minutes before breakfast.

PMNs were isolated from heparinized (10 U/ml heparin, Polfa, Lodz, Poland) whole peripheral blood by Gradisol G gradient $1.115 \mathrm{~g} / \mathrm{ml}$ (Polfa, Lodz, Poland) according to the technique of Zeman (Zeman et al.1988). The isolated cells were suspended in Hank's Balanced Salt solution (Gibco, New York, USA) with a culture medium (BIOMED-Lublin, Poland) containing $8 \%$ autologous serum, $100 \mathrm{U} / \mathrm{ml}$ of penicillin, and $50 \mathrm{ng}$ of streptomycin (Polfa Tarchomin S.A., Poland), to obtain a density of $5 \times 10^{6}$ cells $/ \mathrm{ml}$. For the assessment of NO and cGMP production the cells have been incubated for 20 hours on microplates (Microtest III-Falcon, BD Biosciences, Bedford, USA) at a temperature of $37^{\circ} \mathrm{C}$ in an incubator with a maintained $5 \% \mathrm{CO}_{2}$ flow (NUAIRE'M).

Within 14 days before the study and after seven days of PPI treatment $15 \mathrm{ml}$ of blood was collected to perform the following measurements: NBT test, total nitric oxide (NO) concentration in supernatants obtained from PMNs culture and serum, the cyclic guanosine monophosphate (cGMP) concentration in PMNs supernatants and serum, the PMNs expression of inducible nitric oxide synthase (iNOS) and phospho-p38 MAP kinase.

\section{NBT test}

Nitroblue tetrazolium (NBT, Sigma) was dissolved in phosphate-buffered saline (Biomed). Spontaneous and stimulated NBT tests were performed. PMNs were stimulated by latex (Sigma). The samples were incubated at $37^{\circ} \mathrm{C}$ for 15 minutes (NUAIRETMUS AUTOFLOW $\mathrm{CO} 2$ Water-Jacketed Incubator), and then in room temperature for 15 minutes. The smear was performed and stained with a May-Grunwald-Giemsa solution (Aqua-Med). Under the 40x magnification the number of neutrophils containing the formazan deposit has been 
counted among 100 encountered PMNs; the results has been shown as a percentage of NBT positive cells.

Determination of total NO concentration in PMNs culture supernatants and serum NO production by PMNs was estimated using an indirect method based on the measurement of the nitrite concentration in PMNs culture supernatants and serum according to Griess's reaction. In the analyzed samples nitrate was reduced to nitrite in the presence of cadmium and converted to nitric acid that gave a color reaction with Griess's reagent. After 30 minutes nitrite concentrations were determined by spectrophotometric analysis at $540 \mathrm{~nm}$ with reference to standard curve (Schulz et al.1999). NO concentration in PMNs culture was expressed as $\mu \mathrm{M}$ (supernatant from $10^{6}$ cells suspended in $230 \mu \mathrm{l}$ of culture medium).

Analysis of cGMP concentration in PMNs supernatants and serum

The cGMP level in the PMNs culture supernatants and serum was measured using an enzymelinked immunosorbent assay kit (R\&D Systems $\left.{ }^{\circledR}\right)$.

\section{The expression of iNOS and phospho-p38 MAP kinase}

Freshly isolated PMNs were lysed by sonification (SONICS Vibra Cell) in the presence of protease inhibitor cocktail (Sigma-Aldrich). The lysates were suspended in Laemmli buffer (Bio-Rad Laboratories) and electrophoresed (Bio-Rad Laboratories Mini-PROTEAN® Tetra Cell) on sodium dodecyl sulfate-polyacrylamide gel (Bio-Rad). The resolved protein was transferred onto nitrocellulose (Bio-Rad Laboratories Mini-PROTEAN® Tetra Cell). The nitrocellulose was incubated (Milipore SNAP i.d.TM Protein Detection System) with the primary monoclonal anti-iNOS $(1: 10,000$ R\&D Systems) or polyclonal antibody antiphospho-p38 $\alpha$ MAPK active form (1:10,000 ABR Affinity BioReagents). After washing with 
$0.1 \%$ TBS-T (Bio-Rad Laboratories) the membrane was incubated with alkaline phosphataselabelled anti-mouse or anti-rabbit IgG antibodies (Vector Laboratories). Immunoreactive protein bands were visualized using the 5-bromo-4-chloro-3-indolyl phosphate/nitro blue tetrazolium (BCIP/NBT) Liquid Substrate System (Sigma-Aldrich). The density of iNOS and p38 MAP kinase bands was determined using ImageJ software and quantified with arbitrary units.

\section{Statistical analysis}

The results were analyzed using IBM SPSS Statistics 20.0. The majority of data are expressed as the median with minimal and maximal value. Significance was determined by Wilcoxon signed-rank test and $p<0,05$ was considered significant. This is non-parametric statistical hypothesis test, for the comparison of the medians between two paired samples (before and after specific PPI treatment in the same patient). Data in clinical characteristics of patients have been analyzed by unpaired t-test (age) and Chi-square test (other data).

\section{Results}

\section{Clinical characteristics of the patients}

Thirty patients were enrolled in the study (16 women, 14 men). The two randomized groups were mostly uniform (Table 1).

\section{NBT tests}

We have found no effect of omeprazole and pantoprazole treatment on the results of spontaneous NBT tests (Table 2). However, a statistically significant increase in the 
percentage of phagocytes (by 69\%) has been found in the omeprazole group after PMNs stimulation (NBT test - stimulated). The opposite trend has been observed after pantoprazole treatment but the difference has no reached a statistical significance (Table 2).

Concentration of NO in PMNs culture supernatants and serum

Treatment with omeprazole or pantoprazole had no effect on NO concentration in the PMNs culture supernatant and serum (Table 2).

Concentration of cGMP in PMNs culture supernatants and serum

Treatment with omeprazole or pantoprazole had no effect on cGMP concentration in the PMNs culture supernatant and plasma (Table 2).

iNOS and phosphorylated p38 MAP kinase expression in isolated PMNS

Treatment with omeprazole or pantoprazole had no effect on determined by Western blotting iNOS protein expression (Table 2). Phospho-p38 MAP kinase signal in Western blotting shows only active, doubly phosphorylated forms of this kinase. Treatment with omeprazole or pantoprazole did not stimulate or inhibit p38 MAP kinase activity in PMNs (Table 2).

\section{Discussion}

In PMNs, production of the oxygen reactive species by myeloperoxidase (MPO) and NADPH oxidase play a very important role in phagocytosis (Nauseef 2014). The NADPH oxidase transfers electrons into the phagosome, generating superoxide anion and hydrogen peroxide $\left(\mathrm{H}_{2} \mathrm{O}_{2}\right)$ from molecular oxygen. MPO and $\mathrm{H}_{2} \mathrm{O}_{2}$ react to produce hypochlorous acid ( $\mathrm{HOCl}) . \mathrm{HOCl}$ reacts with peptides and proteins from host and microbe to generate an array 
of products, including monochloramines, protein chloramines, which can then decompose to form aldehydes. These processes are aimed at destruction and decomposition of phagocytosed material. To our knowledge, there are no published studies about the effect of PPIs on all aspects of phagocytosis in PMNs. There are a few reports about the effect of PPIs on superoxide anion production by PMNs, however, their results are conflicting. Earlier in vitro study has shown, that omeprazole reduced PMNs degranulation, chemotaxis and inhibited superoxide anion generation (Wandall 1992). In this study PMNs were isolated from blood of healthy donors, activated by formyl-methionine-leucine-phenylalanine (fMLP) and incubated with omeprazole in varying concentrations, from 10 to 50 minutes. Generation of superoxide anion was inhibited in $50 \%$ by omeprazole at concentration of $2.5 \times 10^{-5} \mathrm{~mol} / 1$ and this effect was maximal after 30 minutes. A similar observation has been made by Capodicasa et al. who found that lansoprazole inhibited in vitro the cytotoxic activity of PMNs, natural killer cells chemotaxis and superoxide anion production (Capodicasa et al. 1999). In this study PMNs were isolated from heparinized blood of 12 healthy volunteers and preincubated for 30 minutes with scaled-up concentrations of lansoprazole. The study showed that lansoprazole at concentration 250, 500 and $1000 \mu \mathrm{M}$ inhibited PMNs superoxide anion generation. In the recent study, the effect of PPIs on peripheral leukocytes function has been studied in patients with decompensated cirrhosis (Garcia-Martinez et al. 2015). Most patients undergoing PPI treatment were on omeprazole (91\%), while esomeprazole and pantoprazole use accounted for $4.5 \%$ of cases each. The blood granulocyte and monocyte's phagocytic activity and oxidative burst were evaluated by flow cytometry. Use of PPIs was associated with a decreased granulocyte and monocyte oxidative burst, but not of phagocytic activity, as compared with patients not receiving PPIs. Interestingly, another in vitro study showed that PPIs, omeprazole and esomeprazole, stimulate production of reactive oxygen species in monocyte-derived macrophages and initiate apoptosis of human B-cell tumors (De 
Milito et al. 2007). In another study of the effect of treatment with $40 \mathrm{mg}$ omeprazole on neutrophils function, PMNs were isolated from venous blood before treatment and 4 hours after drug administration (Zedtwitz-Liebenstein et al. 2002). Extracellular reactive oxygen intermediate production (ROI) was assessed with a cytochrome c reduction assay and neutrophil bactericidal capacity were determined by fluorometry. Omeprazole had no effect on phagocytosis rate and basal extracellular reactive oxygen intermediate production. However, after PMNs stimulation with E.coli the extracellular and intracellular ROI production was impaired by omeprazole (Zedtwitz-Liebenstein et al. 2002). In the present study, with the use of NBT test we have evaluated the function of PMNs phagocytosis and capability to produce oxygen reactive species. We have found that short-term treatment with omeprazole enhances PMNs reactive oxygen species production and thereby may improve phagocytosis. The opposite trend has been observed after pantoprazole treatment but the difference has no reached a statistical significance.

NBT test is known as a semi-quantitative microscopic method for evaluation of reactive oxygen species production used to screen for neutrophil and other phagocytic cells dysfunction. Neutrophils reduce the dye NBT, a clear yellow water-soluble nitro-substituted aromatic tetrazolium compound, to a purple colored formazan derivative upon stimulation of the respiratory burst (Choi et al. 2006; Rook et al. 1985). Formazan precipitates as a dark blue granular substance, which remains trapped in the neutrophil's cytoplasm. Considering the assumed mechanism of formazan formation, the results of NBT test in our study suggest that short-term treatment with omeprazole enhances reactive oxygen species production in PMNs. Our results also indicate that some effects of PPI on PMNs function may be specific to the drug type since pantoprazole treatment resulted in an opposite effect. Currently, it is difficult to predict the clinical significance of this finding. Further studies are necessary to understand the mechanism of PPIs effect on targets other than proton pumps in parietal cells 
in the stomach. PMNs are remarkably short-lived with a circulating half-life of $6-8 \mathrm{~h}$ and the total residence time of these cells in the bone marrow may be around 11 days (Cronkite 1979; Summers et al. 2010). So, even short time treatment with PPI should be sufficient to influence their function. In contrast to majority of previous studies, our current study is an in vivo observation with the alternative method of superoxide anion production measurement. In cultures of PMNs isolated from our patients we have used an autologous serum, but we have not determined omeprazole and pantoprazole level in culture medium. Therefore, we have no evidence if the omeprazole or pantoprazole in vitro level corresponded to concentrations used by the others. We have not evaluated omeprazole and pantoprazole plasma level in our patients. PPIs are metabolized mainly in the liver by cytochrome P450 enzymes, with CYP2C19 playing the dominant role (Kirchheiner et al. 2009). Recently, in another prospective study, we have evaluated cytochrome CYP2C19 genotypes in fifty patients, with upper gastrointestinal bleeding, from our local community (Chwiesko et al. In press). In this group, $12,0 \%$ of subjects were classified into intermediate metabolizers, $46,5 \%$ into extensive metabolizers and $41,5 \%$ into ultrarapid metabolizers and there were no patients with a "poor metabolizer" genotype. So, we can assume that cytochrome CYP2C19 genotypes in patients from our local community do not cover the whole spectrum and are in $88 \%$ represented by fast metabolizers. Therefore, this situation should not lead to dramatic differences in the rate of PPI metabolism in our patients. However, measurements of PPI plasma level would provide additional information about the bioavailability of these drugs.

Our study has demonstrated that treatment with omeprazole and pantoprazole had no effect neither on determined by Western blotting iNOS protein expression in freshly isolated PMNs nor on NO concentration in the PMNs culture supernatant or our patients' sera. There are 
studies suggesting the role of cGMP in inflammatory activity of human neutrophils. It has been shown that increase in cGMP and activation of G-kinase result in chemotaxis occurring via a NO-dependent as well an NO-independent pathway (Wanikiat et al. 1997). The findings obtained in another study have suggested that NO inhibits the activation of human neutrophils through increased production of cGMP (Moilanen et al. 1993). In our study, the results of cGMP concentration measurements are in agreement with NO data showing that treatment with omeprazole or pantoprazole had no effect on cGMP concentration in the PMNs culture supernatant and serum. In the literature, we have found only one report about the effect of PPI on human plasma NO concentration. Interestingly, it has been reported, that treatment with rabeprazole $(20 \mathrm{mg} /$ day) for 8 weeks have caused significant elevation of plasma NO level (Swiatkowski et al. 2004).

Reports in the literature indicate that the activation of cellular p38 MAP kinase was necessary for fMLP-induced chemotaxis ( $\mathrm{Zu}$ et al. 1998). Recently, PMNs from healthy donors blood were incubated with different concentrations of omeprazole and pantoprazole and stimulated to migrate with fMLP and IL-8 (Martins de Oliveira et al. 2007). The activity of p38 MAP kinase was evaluated by Western blot after treatment with omeprazole. Both of PPIs significantly inhibited migration of neutrophils in response to fMPL and IL-8. The cells pretreated with omeprazole showed decreased activity of p38 MAP kinase. The authors of this study have concluded that PPIs promote inhibition of $\mathrm{H}+\mathrm{K}+\mathrm{ATPase}$ in neutrophils, resulting in cationic flow disturbances through the cellular membrane that, consequently, inhibit migratory and intracellular events such as calcium influx and p38 MAP kinase activation (Martins de Oliveira et al. 2007). The effect of omeprazole on expression and activation of MAP kinase family members including p38 MAP kinase in rat gastric mucosal cell line treated for 12 and 24 hours with omeprazole has been also investigated recently $(\mathrm{Ng}$ et al. 2008). This study have showed that omeprazole promoted cell migration, but not cell 
proliferation and had no effect on expression and activation of ERK1/2 and p38 MAP kinase. In our in vivo study, short-term treatment with omeprazole and pantoprazole have had no effect on p38 MAP kinase activity in PMNs freshly isolated from our patients' peripheral blood.

Currently, PPIs are being used all over the world on a huge scale. However, our understanding of the overall activity of PPI beyond the inhibition of gastric acid secretion is still incomplete. Recently, several studies have shown that PPIs such as omeprazole, esomeprazole and pantoprazole have an antineoplastic activity towards human hematopoietic and solid tumors, possibly by rapid induction of reactive oxygen species accumulation through mitochondrial dysfunctions and involvement of NADPH oxidase (De Milito et al. 2007; Marino et al. 2010). The most recent meta-analysis about the association of PPI use with the risk of pneumonia has shown that outpatient PPI use is associated with a 1.5-fold increased risk of community-acquired pneumonia (CAP), with the highest risk within the first 30 days after initiation of therapy (Lambert 2015). CAP risk was absent among participants taking $\mathrm{H} 2$ receptor antagonists, which have weaker acid suppressant activity than do PPIs. This association between CAP risk and short duration of PPI therapy is surprising and difficult to explain. It suggests that some acute changes occurring with onset of PPI therapy may be responsible for CAP risk. Omeprazole and pantoprazole both inhibit the secretion of hydrochloric acid in the stomach with a similar strength. However, the metabolism of these drugs in the liver and interactions with another drugs are to some extent different (Wedemeyer et al. 2014). Until now, the majority of studies about the "extra-gastric" effects of PPIs have been done with the use of omeprazole. In the literature, we did not find any report comparing the effects of different PPI types (omeprazole, pantoprazole, lansoprazole, rabeprazole, etc.) on the risk of pneumonia or Clostridium difficile infection. In our study, we have found different effect of omeprazole and pantoprazole on the stimulated NBT test 
results. Since, the results of NBT test show the ability of neutrophil and other phagocytic cells to phagocytose and kill invading microorganisms, the risk of infections may be different in omeprazole and pantoprazole users. Therefore, there is a rationale and need for clinical and epidemiological studies comparing the "extra-gastric" effects of different PPI types.

In conclusion, there are differences in effects of omeprazole and pantoprazole on PMNs function. Short-term treatment with omeprazole but not with pantoprazole enhances PMNs short-term treatment with omeprazole but not with pantoprazole enhances PMNs reactive oxygen species production. Treatment with PPI has no effect on NO production and p38 mitogen-activated protein kinase activity in PMNs. Further and more detailed studies are necessary on the in vivo effect of PPI beyond inhibition of gastric acid secretion.

\section{Acknowledgements}

This work has been supported with grants from Medical University of Bialystok (Grant 351820) and National Science Centre (Grant NN402456739).

\section{References}

Abraham, E. 2005. Alterations in cell signaling in sepsis. Clin. Infect. Dis. 41 Suppl 7: S459464. PMID: 16237648

Agastya, G., West, B.C., and Callahan, J.M. 2000. Omeprazole inhibits phagocytosis and acidification of phagolysosomes of normal human neutrophils in vitro. Immunopharmacol. Immunotoxicol. 22(2): 357-372. PMID: 10952036

Alderton, W.K., Cooper, C.E., and Knowles, R.G. 2001. Nitric oxide synthases: structure, function and inhibition. Biochem. J. 357(3): 593-615. PMID: 11463332

Capodicasa, E., De Bellis, F., and Pelli, M.A. 1999. Effect of lansoprazole on human leukocyte function. Immunopharmacol. Immunotoxicol. 219(2): 357-377. PMID:10319286

Choi, H.S., Kim, J.W., Cha, Y.N., and Kim, C. 2006. A quantitative nitroblue tetrazolium assay for determining intracellular superoxide anion production in phagocytic cells. J. Immunoass. Immunochem. 27(1): 31-44. PMID:16450867

Chwiesko, A., Charkiewicz, R., Niklinski, J., Luczaj, W., Skrzydlewska E., Milewski R., et al. 2016. Effects of different omeprazole dosing on gastric $\mathrm{pH}$ in nonvariceal upper 
gastrointestinal bleeding: A randomized prospective study. J. Dig. Dis. 17(9): 588-599. PMID: 27518195

Cronkite, E.P. 1979. Kinetics of granulocytopoiesis. Clin. Haematol. 8(2): 351-370. PMID: 385200

Cunningham, R., Dale, B., Undy, B., and Gaunt, N. 2003. Proton pump inhibitors as a risk factor for Clostridium difficile diarrhoea. J. Hosp. Infect. 54(3): 243-245. PMID: 12855243

De Milito, A., Iessi, E., Logozzi, M., Spada, M. Marino, M.L et al. 2007. Proton pump inhibitors induce apoptosis of human B-cell tumors through a caspase-independent mechanism involving reactive oxygen species. Cancer Res. 67(11): 5408-5417. PMID: 17545622

Dial, S., Delaney, J.A., Barkun, A.N., and Suissa, S. 2005. Use of gastric acid - suppressive agents and the risk of community-acquired Clostridium difficile-associated disease. JAMA 294(23): 2989-2995. PMID: 16414946

Dröge, W. 2002. Free radicals in the physiological control of cell function. Physiol. Rev 82(1): 47-95. PMID: 11773609

Garcia-Martinez, I., Francés, R., Zapater, P., Gimenez, P., Gomez-Hurtado, I., Moratalla, A. et al. 2015. Use of proton pump inhibitors decrease cellular oxidative burst in patients with decompensated cirrhosis. J. Gastroenterol. Hepatol. 30(1): 147-154. PMID: 25039465

Gulmez, S.E., Holm, A., Frederiksen, H., Jensen, T.G., Pedersen, C., and Hallas, J. 2007. Use of proton pump inhibitors and the risk of community-acquired pneumonia: a population-based case-control study. Arch. Intern. Med. 167(9): 950-955. PMID: 17502537

Kirchheiner, J., Glatt, S., Fuhr, U, Klotz, U., Meineke, I., Seufferlein, T. et al. 2009. Relative potency of proton-pump inhibitors-comparison of effects on intragastric pH. Eur. J. Clin. Pharmacol. 65(1): 19-31. PMID: 18925391

Koshio, O., Tansho, S., Ubagai, T., and Nakaki, T. 2010. Suppression of phosphorylation of extracellular-signal-regulated kinase and p38 mitogen-activated protein kinase in polymorphonuclear leukocytes by the proton pump inhibitor lansoprazole. J. Infect. Chemother. 16(2): 100-106. PMID: 20094750

Laheij, R., Sturkenboom, M., Hassing, R-J., Dieleman, J., Stricker, B., and Jansen, J.B. 2004. Risk of community-acquired pneumonia and use of gastric acid-suppressive drugs. JAMA 292(16): 1955-1960. PMID: 15507580

Lambert, A.A., Lam, J.O., Paik, J.J., Ugarte-Gil, C., Drummond, M.B., and Crowell, T.A. 2015 Risk of community-acquired pneumonia with outpatient proton-pump inhibitor therapy: a systematic review and meta-analysis. PLoS One, 10(6): e0128004. PMID: 26042842 
Marino, M.L., Fais, S., Djavaheri-Mergny, M., Villa, A., Meschini, S., Lozupone, F. et al. 2010. Proton pump inhibition induces autophagy as a survival mechanism following oxidative stress in human melanoma cells. Cell Death Dis. 1: e87. PMID: 21368860

Martin, R.M., Dunn, N.R., Freemantle, S., and Shakir, S. 2000. The rates of common adverse events reported during treatment with proton pump inhibitors used in general practice in England: cohort studies. Br. J. Clin. Pharmacol. 50(4): 366-372. PMID: 11012560

Martins de Oliveira,R., Antunes, E., Pedrazzoli, J. Jr., and Gambero, A. 2007. The inhibitory effects of $\mathrm{H}+\mathrm{K}+\mathrm{ATPase}$ inhibitors on human neutrophils in vitro: Restoration by $\mathrm{K}+$ ionophore. Inflamm. Res. 56(3): 105-111. PMID:17406807

Moilanen, E., Vuorinen, P., Kankaanranta, H., Metsä-Ketelä, T., and Vapaatalo, H. 1993. Inhibition by nitric oxide-donors of human polymorphonuclear leucocyte functions. Br. J. Pharmacol. 109(3): 852-858. PMID: 8395300

Nauseef, W.M. 2014. Myeloperoxidase in human neutrophil host defense. Cell Microbiol. 16(8): 1146-1155. PMID: 24844117

Ng, K.M., Cho, C.H., Chang, F.Y., Luo, J.C., Lin, H.C., Lin, H.Y. et al. 2008. Omeprazole promotes gastric epithelial cell migration. J. Pharm. Pharmacol. 60(5): 655-660.

PMID:18416943

Ritter, M., Schratzberger, P., Rossman, H., Wöll, E., Seiter, K., Seidler, U. et al. 1998. Effect of inhbitors of $\mathrm{Na}+/ \mathrm{H}+-$ exchange and gastric $\mathrm{H}+/ \mathrm{K}+$ ATPase on cell volume, intracellular $\mathrm{pH}$ and migration of human polymorphonuclear leucocytes. Br. J. Pharmacol. 124(4): 627-638.

PMID: 9690853

Rook, G.A., Steele, J., Umar, S., and Dockrell, H.M. 1985. A simple method for the solubilisation of reduced NBT, and its use as a colorimetric assay for activation of human macrophages by gamma-interferon. J. Immunol. Meth. 82(1): 161-167. PMID: 3928762

Schulz, K., Kerber, S., and Kelm, M. 1999. Reevaluation of the Griess method for determing NO/NO2- in aqueous and protein containing samples. Nitric Oxide, 3(3): 225-234. PMID: 10442854

Stedman, C.A., and Barclay, M.L. 2000. Review article: comparison of the pharmacokinetics, acid suppression and efficacy of proton pump inhibitors. Aliment. Pharmacol. Ther. 14(8): 963-978. PMID: 10930890

Summers, C., Rankin, S.M., Condliffe, A.M., Singh, N., Peters, A.M., and Chilvers ER. 2010. Neutrophil kinetics in health and disease. Trends. Immunol. 31(8): 318-324. PMID:

20620114 
Suzuki, M., Mori, M., Fukumura, D., Suzuki, H., Miura, S., and Ishii, H. 1999. Omeprazole attenuates neutrophil-endothelial cell adhesive interaction induced by extracts of Helicobacter pylori. J. Gastroenterol. Hepatol. 14(1): 27-31. PMID: 10029274

Suzuki, M., Mori, M., Miura, S., Suematsu, M., Fukumura, D., Kimura, H. et al. 1996. Omeprazole attenuates oxygen-derived free radical production from human neutrophils. Free Radic. Biol. Med. 21(5): 727-731. PMID: 8891677

Swiatkowski, M., Budzyński, J., Kłopocka, M., Grad, K., Pulkowski, G., Augustyńska, B. et al. 2004. The effect of eight weeks of rabeprazole therapy on nitric oxide plasma level and esophageal $\mathrm{pH}$ and motility and motility nitric oxide plasma level in patients with erosive esophagitis. Med. Sci. Monit. 10(2): 46-51. PMID: 14737042.

Tsai, E.J., and Kass, D.A. 2009. Cyclic GMP signaling in cardiovascular pathophysiology and therapeutics. Pharmacol. Ther. 122(3): 216-238. PMID: 19306895.

Wandall, J.H. 1992. Effects of omeprazole on neutrophil chemotaxis, super oxide productions, degranulation, and translocation of cytochrome b-245. Gut, 33(5): 617-621. PMID: 1319381.

Wanikiat, P., Woodward D.F., and Armstrong R.A. 1997. Investigation of the role of nitric oxide and cyclic GMP in both the activation and inhibition of human neutrophils. Br. J. Pharmacol. 122(6): 1135-1145. PMID: 9401778.

Wedemeyer, R.S., and Blume H. 2014. Pharmacokinetic drug interaction profiles of proton pump inhibitors: an update. Drug Saf. 37(4): 201-211. PMID: 24550106.

Yearsley, K.A., Gilby, L.J., Ramadas, A.V., Kubiak, E.M., Fone, D.L., and Allison, M.C. 2006. Proton pump inhibitor therapy is a risk factor for Clostridium difficile-associated diarrhea. Aliment. Pharmacol. Ther. 24(4): 613-619. PMID: 16907893.

Yoshida, N., Yoshikava, T., Tanaka, Y., Fujita, N., Kassai,K., Naito, Y. et al. 2000. A new mechanism for anti-inflammatory actions of proton pump inhibitors - inhibitory effects on neutrophil-endothelial cell interactions. Aliment. Pharmacol. Ther. 14 (Suppl 1): 74-81. PMID: 10807407.

Zedtwitz-Liebenstein, K., Wenisch, C., Patruta, S., Parschalk, B., Daxböck, F., and Graninger, W. 2002. Omeprazole treatment diminishes intra- and extracellular neutrophil reactive oxygen production and bactericidal activity. Crit. Care Med. 30(5): 1118-1122. PMID: 12006811.

Zeman, K., Tchorzewski, H., and Majewska, E. 1988. Simple and fast method of simultaneous isolation of lymphocytes and the polymorphonuclear cells from peripheral blood. Immunol. Pl. 13: 217-225.

Zu, Y.L., Qi, J., Gilchrist, A., Fernandez, G.A., Vazquez-Abad, D., Kreutzer, D.L. et al. 1998. p38 mitogen-activated protein kinase activation is required for human neutrophil function 
triggered by TNF-alpha or FMLP stimulation. J. Immunol. 160(4): 1982-1989. PMID: 9469462 
Table 1 Clinical characteristics of patients.

\begin{tabular}{|l|l|l|l|}
\hline & $\begin{array}{l}\text { Omeprazole } \\
\text { group }\end{array}$ & $\begin{array}{l}\text { Pantoprazole } \\
\text { group }\end{array}$ & $p$ value \\
\hline & $n=15$ & $n=15$ & \\
\hline Age (mean \pm SD) & $41.5 \pm 15.0$ & $34.3 \pm 8.6$ & 0.110 \\
\hline Male & 8 & 6 & 0.460 \\
\hline Medical history & & & \\
\hline heartburn & 12 & 13 & 0.620 \\
\hline epigastric pain & 8 & 7 & 0.720 \\
\hline chest pain & 4 & 4 & 1.000 \\
\hline cough & 1 & 1 & 1.000 \\
\hline hoarseness & 2 & 1 & 0.540 \\
\hline Comorbidities & & & \\
\hline arterial hypertension & 7 & 6 & 0.710 \\
\hline coronary artery disease & 1 & 1 & 1.000 \\
\hline Medication before admission & & & \\
\hline PPI & 9 & 10 & 0.700 \\
\hline H2 antagonist & 4 & 3 & 0.670 \\
\hline NSAID & 1 & 2 & 0.540 \\
\hline antihypertensive agents & 6 & 5 & 0.700 \\
\hline statins & 1 & 1 & 1.000 \\
\hline Active smokers & 5 & 4 & 0.690 \\
\hline
\end{tabular}

PPI: proton pump inhibitor; $\mathrm{H} 2$ antagonist: histamine $\mathrm{H} 2$ receptor antagonist; NSAID: nonsteroidal anti-inflammatory drugs 
Table 2. The effect of omeprazole and pantoprazole treatment on the NBT test results, the level of NO and cGMP in PMNs culture supernatant and serum as well as expression of inducible nitric oxide synthase (iNOS) and phospho-p38 MAP kinase in freshly isolated PMNs.

\begin{tabular}{|c|c|c|c|c|c|}
\hline & $\begin{array}{l}\text { Before } \\
\text { treatment with } \\
\text { omeprazole } \\
(n=15)\end{array}$ & $\begin{array}{l}\text { After } \\
\text { treatment with } \\
\text { omeprazole } \\
(n=15)\end{array}$ & $\begin{array}{l}\text { Before } \\
\text { treatment with } \\
\text { pantoprazole } \\
(n=15)\end{array}$ & $\begin{array}{l}\text { After treatment } \\
\text { with } \\
\text { pantoprazole } \\
(n=15)\end{array}$ & $\begin{array}{l}\text { Statistical } \\
\text { significance }\end{array}$ \\
\hline & 1 & 2 & 3 & 4 & \\
\hline $\begin{array}{l}\text { NBT test } \\
\text { spontaneous (\%) }\end{array}$ & $\begin{array}{l}6.00 \\
(2.00-48.00)\end{array}$ & $\begin{array}{l}9.00 \\
(5.00-28.00)\end{array}$ & $\begin{array}{l}8.00 \\
(1.00-42.00)\end{array}$ & $\begin{array}{l}7.00 \\
(2.00-44.00)\end{array}$ & $\begin{array}{l}1 \text { (1 } v s \text { 2) } 0.208 \\
(3 v s \text { 4) } 0.649\end{array}$ \\
\hline $\begin{array}{l}\text { NBT test stimulated } \\
(\%)\end{array}$ & $\begin{array}{l}16.00 \\
(6.00-73.00)\end{array}$ & $\begin{array}{l}27.00 \\
(6.00-74.00)\end{array}$ & $\begin{array}{l}21.00 \\
(7.00-72.00)\end{array}$ & $\begin{array}{l}16.00 \\
(4.00-72.00)\end{array}$ & $\begin{array}{l}(1 v s 2) \mathbf{0 . 0 4 4} \\
(3 v s 4) 0.589\end{array}$ \\
\hline $\begin{array}{l}\text { NO in PMNs culture } \\
(\mu \mathrm{M})\end{array}$ & $\begin{array}{l}24.43 \\
(4.71-42.61)\end{array}$ & $\begin{array}{l}22.16 \\
(6.82-65.22)\end{array}$ & $\begin{array}{l}25.00 \\
(14.21-85.87)\end{array}$ & $\begin{array}{l}20.46 \\
(6.25-28.41)\end{array}$ & $\begin{array}{l}1 \text { (1 } v s \text { 2) } 0.910 \\
(3 v s 4) 0.109\end{array}$ \\
\hline NO in serum $(\mu \mathrm{M})$ & $\begin{array}{l}33.52 \\
(5.99-77.17)\end{array}$ & $\begin{array}{l}28.41 \\
(14.77-89.19)\end{array}$ & $\begin{array}{l}49.43 \\
(15.34-82.61)\end{array}$ & $\begin{array}{l}50.54 \\
(14.77-257.61)\end{array}$ & $\begin{array}{l}(1 v s 2) \\
(1 v .712 \\
(3 v s 4) \\
1.000\end{array}$ \\
\hline $\begin{array}{l}\text { cGMP in PMNs } \\
\text { culture }(\mathrm{pM} / \mathrm{ml})\end{array}$ & $\begin{array}{l}2.59 \\
(0.61-8.51)\end{array}$ & $\begin{array}{l}2.73 \\
(0.09-5.68)\end{array}$ & $\begin{array}{l}3.03 \\
(0.70-5.31)\end{array}$ & $\begin{array}{l}2.94 \\
(0.26-4.61)\end{array}$ & 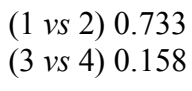 \\
\hline $\begin{array}{l}\text { cGMP in serum } \\
(\mathrm{pM} / \mathrm{ml})\end{array}$ & $\begin{array}{l}5.13 \\
(4.47-390.41)\end{array}$ & $\begin{array}{l}5.44 \\
(4.20-139.93)\end{array}$ & $\begin{array}{l}36.84 \\
(5.66-1545.37)\end{array}$ & $\begin{array}{l}58.71 \\
(5.43-1465.37)\end{array}$ & $\begin{array}{l}1 \text { (1 } v s \text { 2) } 0.953 \\
(3 v s 4) 0.386\end{array}$ \\
\hline $\begin{array}{l}\text { iNOS } \\
\text { (arbitrary units } \times 10^{3} \text { ) }\end{array}$ & $\begin{array}{l}14.10 \\
(5.60-102.68)\end{array}$ & $\begin{array}{l}10.60 \\
(5.50-123.14)\end{array}$ & $\begin{array}{l}9.80 \\
(5.10-228.62)\end{array}$ & $\begin{array}{l}11.00 \\
(4.90-211.62)\end{array}$ & 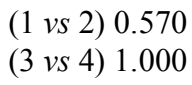 \\
\hline $\begin{array}{l}\text { p38 MAP kinase } \\
\left(\text { arbitrary units } x 10^{3} \text { ) }\right.\end{array}$ & $\begin{array}{l}17.98 \\
(4.20-229.10)\end{array}$ & $\begin{array}{l}16.98 \\
(4.60-232.73)\end{array}$ & $\begin{array}{l}16.20 \\
(7.00-305.05)\end{array}$ & $\begin{array}{l}18.00 \\
(7.20-339.36)\end{array}$ & $\begin{array}{l}(1 v s \quad 2) \\
(3 v s 4) \\
(3 v 842\end{array}$ \\
\hline
\end{tabular}

The data are shown as median (minimum-maximum); NBT - nitroblue tetrazolium; PMNs polymorphonuclear neutrophils; NO - nitric oxide; cGMP - cyclic guanosine monophosphate; inducible nitric oxide synthase (iNOS). 